\title{
Profile of farletuzumab and its potential in the treatment of solid tumors
}

This article was published in the following Dove Press journal:

OncoTargets and Therapy

7 March 2016

Number of times this article has been viewed

\author{
Seiya Sato \\ Hiroaki Itamochi \\ Department of Obstetrics and \\ Gynecology, Iwate Medical University \\ School of Medicine, Morioka, Japan
}

Correspondence: Hiroaki Itamochi Department of Obstetrics and Gynecology, Iwate Medical University School of Medicine, 19-I Uchimaru, Morioka 020-8505, Iwate, Japan

$\mathrm{Tel}+8 \mid$ | $965|5||| \mid$

Fax +81196221900

Email itamochi@iwate-med.ac.jp
Abstract: Folate receptor (FR) $\alpha$ expression in normal tissues is restricted to a subpopulation of epithelial cells. In contrast, FR $\alpha$ is overexpressed in epithelial ovarian cancer (EOC) and non-small-cell lung carcinoma. Therefore, FR $\alpha$ is considered a promising therapeutic target for EOC and non-small-cell lung carcinoma. Farletuzumab (MORAb-003) is a humanized monoclonal antibody of immunoglobulin G subtype 1 kappa, targeting human FR $\alpha$. To date, Phase I/II clinical trials have clearly demonstrated the feasibility and safety of farletuzumab as a treatment option against solid tumors. However, in Phase III clinical trial that was conducted to verify the combined effect of paclitaxel-carboplatin combination therapy and farletuzumab for patients with recurrent EOC, improvement in progression-free survival was not statistically significant. This result might be owing to the fact that the eligibility criteria for these studies did not include FR $\alpha$ expression. The significance of FR $\alpha$ as a predictive/prognostic biomarker remains unclear. In addition, there is currently no established biomarker to predict the response and toxicities among patients receiving farletuzumab therapy. Furthermore, the primary mechanism of action of farletuzumab has not yet been identified. Therefore, further research to identify the mechanism of farletuzumab in tumor suppression is necessary to clarify the full potential of this chemotherapeutic agent.

Keywords: immunoglobulin G subtype 1 kappa, folate receptor $\alpha$, monoclonal antibody, targeted therapy, epithelial ovarian cancer, non-small-cell lung carcinoma

\section{Introduction}

DNA synthesis in cancer cells is highly dependent on folate, whereas folate receptor (FR) $\alpha$ expression in normal tissues is restricted to a subpopulation of epithelial cells. $^{1,2}$ In contrast, FR $\alpha$ is overexpressed in nearly $90 \%$ of epithelial non-mucinous ovarian cancers and has been correlated with tumor stage and grade, chemotherapeutic response, and treatment outcome. ${ }^{3}$ In addition, $\mathrm{FR} \alpha$ expression is retained in recurrent tumors and metastatic lesions. ${ }^{4}$ Among lung cancers, FR $\alpha$ expression is increased in non-small-cell lung carcinoma (NSCLC) ${ }^{5}$ and is higher in adenocarcinomas than in squamous cell carcinomas. ${ }^{6}$ Hence, FR $\alpha$ is considered a promising therapeutic target for epithelial ovarian cancer $(\mathrm{EOC})^{7}$ and NSCLC. ${ }^{8}$

Farletuzumab (MORAb-003), a humanized monoclonal antibody of immunoglobulin G subtype 1 kappa that targets human FR $\alpha,{ }^{9}$ was derived by optimizing the FR $\alpha$-binding murine antibody LK26, which has high affinity for FR $\alpha .{ }^{10}$ A profile of farletuzumab is summarized in Table 1. Farletuzumab is considered to induce immune-dependent cell death, although no underlying mechanism has yet been clarified. ${ }^{11}$ Farletuzumab has shown efficacy in both preclinical and clinical studies as a single agent and in combination chemotherapy with minimal drug-specific toxicity. ${ }^{12}$ However, no improvement in progression-free survival (PFS) was observed in Phase III clinical 
Table I Profile of farletuzumab

\begin{tabular}{|c|c|c|}
\hline Development code & \multicolumn{2}{|l|}{ MORAb-003 } \\
\hline Target & \multicolumn{2}{|l|}{ Folate receptor $\alpha$} \\
\hline Drug class & \multicolumn{2}{|c|}{ Humanized monoclonal antibody } \\
\hline Molecular weight & \multicolumn{2}{|c|}{$145 \mathrm{kDa}$} \\
\hline Immunoglobulin (Ig) & \multicolumn{2}{|l|}{$\operatorname{lgGI} / \kappa$} \\
\hline \multirow[t]{5}{*}{ Mechanism } & \multicolumn{2}{|c|}{ Antibody-dependent cellular cytotoxicity } \\
\hline & \multicolumn{2}{|c|}{ Complement-dependent cytotoxicity } \\
\hline & \multicolumn{2}{|c|}{ Inhibition of interaction between $\mathrm{FR} \alpha$ and } \\
\hline & \multicolumn{2}{|c|}{ Lyn kinase } \\
\hline & \multicolumn{2}{|c|}{ Induces cell death associated with autophagy } \\
\hline Administration & \multicolumn{2}{|l|}{ Intravenous injection } \\
\hline Recommended dose & \multicolumn{2}{|l|}{$2.5-10 \mathrm{mg} / \mathrm{kg}$} \\
\hline$C_{\max }$ & \multicolumn{2}{|l|}{ 6.88-287.I $\mu \mathrm{g} / \mathrm{mL}$} \\
\hline Half-life & \multicolumn{2}{|l|}{$121-260$ hours (estimated) } \\
\hline Common adverse & Hypersensitivity reactions & $60 \%$ \\
\hline \multirow[t]{5}{*}{ events $^{\mathrm{a}}$} & Pyrexia & $32 \%$ \\
\hline & Chills & $20 \%$ \\
\hline & Headache & $8 \%$ \\
\hline & Fatigue & $48 \%$ \\
\hline & Diarrhea & $16 \%$ \\
\hline
\end{tabular}

Note: ${ }^{a}$ All events were grade I or 2.

Abbreviations: $F R \alpha$, folate receptor $\alpha ; C_{\max }$, peak plasma concentration of a drug after administration. trials that were conducted to verify the combined effect of cytotoxic drugs and farletuzumab. ${ }^{13}$ This result might be because the eligibility criteria for these study did not include FR $\alpha$ expression. ${ }^{2}$ Hence, there is a need for appropriate patient selection based on predictive biomarkers to clarify the potential of FR $\alpha$ expression in the clinical setting. In this review, we describe preclinical and clinical data related to farletuzumab and update recent findings.

\section{Preclinical data on farletuzumab}

An in vitro study found that farletuzumab did not inhibit binding of folic acid and antifolates to FR $\alpha$ and that it had no significant effect on cell growth or folate uptake via FR $\alpha .{ }^{14}$ The proposed mechanism of farletuzumab-induced cell toxicity shown in Figure 1 suggests that farletuzumab inhibits FR $\alpha$-dependent cell growth in a dose-dependent manner and exhibits tumor cytotoxicity through complementdependent cytotoxicity (CDC) and antibody-dependent cellular cytotoxicity. ${ }^{9}$ Farletuzumab has also been shown to inhibit the interaction between cytoplasmic tyrosine kinase Lyn and

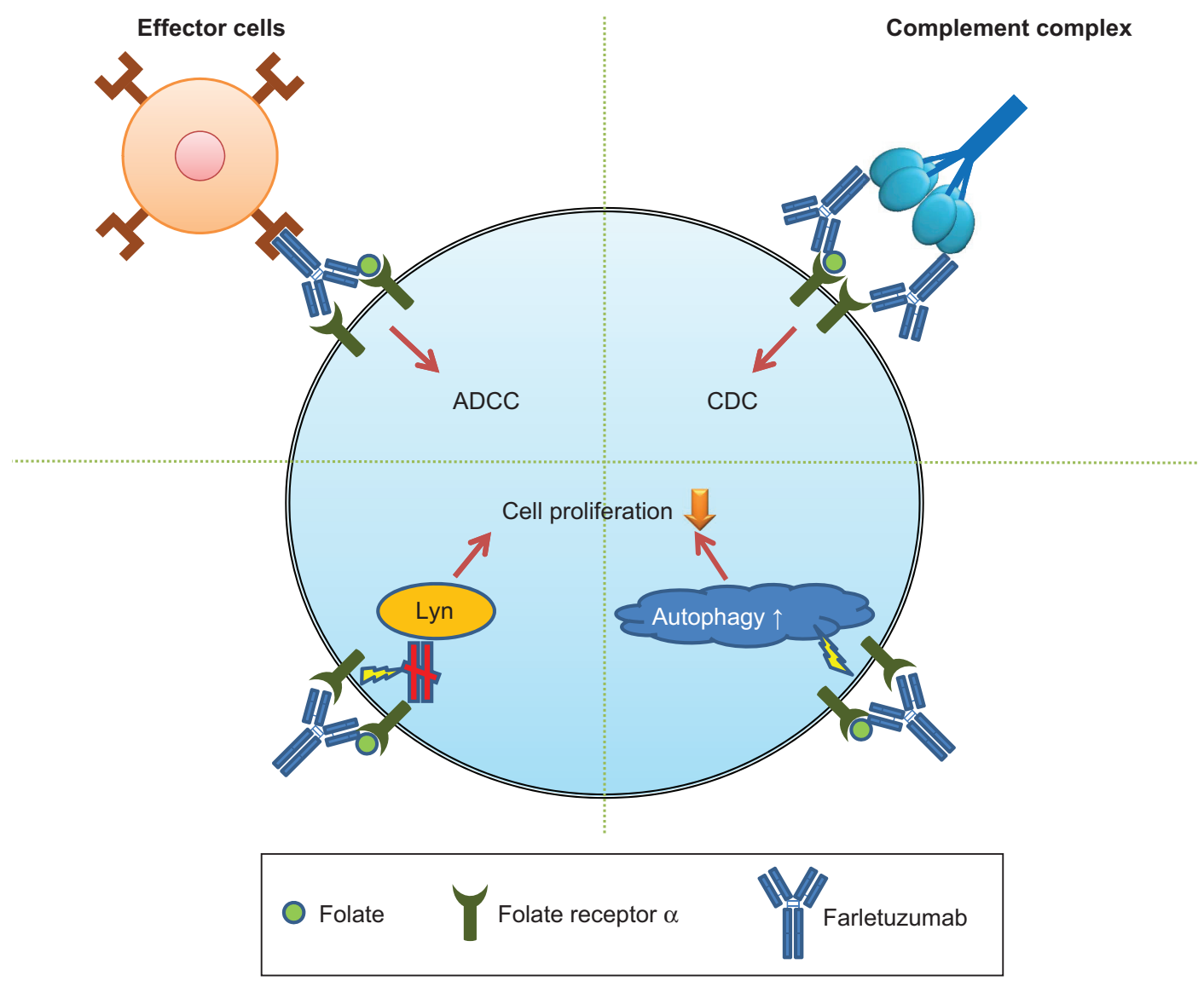

Figure I Schema of the mechanism of farletuzumab-induced cell toxicity.

Notes: Farletuzumab mediates tumor cytotoxicity through ADCC and CDC. Farletuzumab was also shown to inhibit the intracellular association of Lyn kinase and folate receptor $\alpha$, thereby reducing the growth advantage of these cells. Furthermore, farletuzumab inhibited tumor growth via induction of autophagy-associated cell death. Abbreviations: ADCC, antibody-dependent cellular cytotoxicity; CDC, complement-dependent cytotoxicity. 
membrane-signaling complexes; this results in a reduction in the growth of these cells. ${ }^{15}$ A recent preclinical study, ${ }^{16}$ which found that farletuzumab inhibited tumor growth via induction of autophagy-associated cell death, demonstrated this inhibitory effect in three-dimensional in vitro models and showed that farletuzumab reduced tumor cell proliferation but had no significant effect on apoptosis, suggesting that blockade of FR $\alpha$ by farletuzumab induced sustained autophagy and suppressed cell proliferation.

\section{Clinical data on ovarian cancer}

Among gynecological malignancies, EOC is the most difficult to cure. ${ }^{17,18}$ The standard treatment for advanced EOC is maximum tumor debulking and systemic chemotherapy. ${ }^{19,20}$ Although $>80 \%$ of patients respond to paclitaxel-carboplatin combination therapy, most will relapse. ${ }^{21}$ Because the prognosis of advanced EOC remains poor, new agents are urgently needed to improve treatment outcome. ${ }^{22}$ Toward this goal, farletuzumab is currently among the most promising drugs for EOC, as evidenced in several clinical trials.

\section{Phase I studies MORAb-003-00 I (NCT00428766)}

In this Phase I dose-escalation study, ${ }^{23}$ farletuzumab was intravenously administered to 25 patients with platinumrefractory or platinum-resistant EOC to assess the safety of weekly administration of $12.5-400 \mathrm{mg} / \mathrm{m}^{2}$ on days $1,8,15$, and 22 and to determine the maximum tolerated dose. Drug efficacy was assessed using Response Evaluation Criteria in Solid Tumors (RECIST) and by monitoring serum cancer antigen (CA) 125 levels and evaluating pharmacokinetics of the drug. Because there was no dose-limiting toxicity, which is defined by the occurrence of grade $\geq 3$ treatment-related adverse events (AEs), maximum tolerated dose was not determined. Therefore, a recommended dosage was not determined in this study. Given that $400 \mathrm{mg} / \mathrm{m}^{2}$ substantially corresponds to a weight-based dosing of $10-12 \mathrm{mg} / \mathrm{kg}$, a dosage of $2.5-10 \mathrm{mg} / \mathrm{kg}$ was adopted in a Phase II clinical trial.

Although AEs were generally mild, grade $1 / 2$ treatmentrelated AEs were observed in 20 patients $(80.0 \%)$; however, there were no severe (grade $\geq 3$ ) treatment-related AEs. The most common treatment-related AEs and drug hypersensitivity AEs are shown in Table 1. Drug hypersensitivity reactions were mild and managed with antipyretics and/or antihistamines. Efficacy was assessed at 4 weeks after cessation of treatment. No objective responses were observed. Of the 24 surviving patients who were included in this trial, stable disease was observed in nine (36\%) and disease progression was observed in 15 (60\%), while decreased CA125 levels were observed in four (17\%). A population pharmacokinetic analysis revealed that body weight was the only investigated covariate, which explained inter-patient variability in disease clearance and central volume of distribution. ${ }^{24}$

\section{MORAb-003-005 (NCT0I004380)}

This Phase I study ${ }^{25}$ evaluated the safety of combination therapy with farletuzumab, carboplatin, and pegylated liposomal doxorubicin (PLD) in subjects with platinum-sensitive EOC. In this study, 15 patients who relapsed after $>6$ months after the completion of first- or second-line platinum-based chemotherapy were enrolled. All patients received six cycles of carboplatin (area under the curve [AUC] of 5-6) and PLD $\left(30 \mathrm{mg} / \mathrm{m}^{2}\right)$ on day 1 of every 4 -week combination treatment cycle. The patients also received weekly intravenous injections of farletuzumab at $2.5 \mathrm{mg} / \mathrm{kg}$. Following the completion of carboplatin/PLD/farletuzumab therapy, maintenance treatment with $7.5 \mathrm{mg} / \mathrm{kg}$ farletuzumab was administered triweekly until disease progression. Among this cohort, there were no severe AEs, although anemia was observed in 14 (93\%) patients; moreover, fatigue and hand-foot syndrome were observed in eight patients $(53 \%)$. No increase in the incidence of side effects associated with the combination of farletuzumab and cytotoxic drugs was observed. Further clinical trials on the efficacy of this regimen are expected.

\section{NCT0I04906।}

This Phase I study ${ }^{26}$ assessed the safety and tolerability of farletuzumab among Japanese patients with solid tumors that express FR $\alpha$. Pharmacokinetic profiles were also examined. Sixteen patients (14 with EOC and two with gastric cancer) were enrolled in this study. Farletuzumab (50, 100, 200, and $400 \mathrm{mg} / \mathrm{m}^{2}$ ) was intravenously administered weekly until tumor progression. No dose-limiting toxicity was observed among the study participants, and there were no severe AEs. Grade 1/2 infusion-related reactions were observed in $15(93.8 \%)$ patients, and headache was observed in seven $(43.8 \%)$. Furthermore, nausea and appetite loss were observed in five (31.3\%) patients, respectively. Pharmacokinetic profiles in this study were similar to those in previous reports. Together, these results suggest that farletuzumab is also well tolerated by Japanese patients.

\section{Phase II studies MORAb-003-002 (NCT003 I 8370)}

This Phase II study evaluated the efficacy of farletuzumab treatment alone and in combination with chemotherapy, 
which consists of taxane and platinum, in patients with platinum-sensitive relapsed EOC. ${ }^{27}$ For six cycles over a 21-day interval, 54 evaluable patients received weekly farletuzumab alone or in combination with chemotherapy, followed by weekly doses of farletuzumab maintenance until disease progression. The primary end points were normalization of CA125 levels and overall response rate. A serologic response (change in CA125) was defined using the modified Gynecologic Cancer Intergroup (GCIG) criteria. Furthermore, the interval of secondary responses was compared with the duration of the first response.

Of the 54 patients enrolled in this study, 47 (87\%) received combination chemotherapy. In 38 (70\%) patients, CA125 levels normalized after six cycles of combination therapy. Forty-three ( $80 \%$ ) patients were evaluated based on RECIST. In these patients, the overall response rate was $70 \%$ (complete response, 7\%; partial response, 63\%). Notably, a second remission that was longer than their first remission was observed in nine $(21 \%)$ of 44 evaluable patients. Furthermore, the response rate was high among patients with a first progression-free interval of $<12$ months. The results of this study suggested that farletuzumab combined with standard chemotherapy improves the response rate and progression-free interval in platinum-sensitive EOC patients.

\section{MORAb-003-0I I (NCT02289950)}

This Phase II global, multicenter, double-blind, randomized, placebo-controlled study is underway to assess the safety and efficacy of farletuzumab in platinum-sensitive subjects in their first relapse with high-grade serous EOC and low CA125 levels. In this trial involving a target enrollment of 210 patients, weekly farletuzumab at a dosage of $5 \mathrm{mg} / \mathrm{kg}$ is being compared with a placebo in combination with chemotherapy (carboplatin + paclitaxel or carboplatin + PLD). The primary end point is PFS based on RECIST, and secondary endpoints are overall survival (OS), length of first vs second platinum-free interval, and tumor response.

\section{Phase III studies MORAb-003-003 (NCT00738699)}

This Phase III randomized, placebo-controlled trial ${ }^{28}$ assessed the efficacy and safety of farletuzumab in combination with weekly paclitaxel in patients with platinumresistant recurrent or refractory EOC (Table 2) to determine whether paclitaxel is more efficacious when administered alone or in combination with farletuzumab. The primary end point was 2-year PFS. This study was terminated early after recruiting 417 patients because the study did not meet the prespecified criteria for continuation following interim futility analysis.

\section{MORAb-003-004 (NCT00849667)}

This Phase III randomized, double-blind, placebo-controlled trial compared the efficacy and safety of six cycles of carboplatin and taxane (paclitaxel or docetaxel) with and without weekly farletuzumab in patients with a first platinum-sensitive relapse of EOC (Table 2). A total of 1,100 women were randomized to the following three arms: $1.25 \mathrm{mg} / \mathrm{kg}$ farletuzumab plus combination therapy, $2.5 \mathrm{mg} / \mathrm{kg}$ farletuzumab

Table 2 Characteristics of Phase III trial of farletuzumab for non-mucinous ovarian cancer including primary peritoneal or fallopian tube malignancies

\begin{tabular}{|c|c|c|}
\hline Identifier & NCT00738699 & NCT00849667 \\
\hline Confirmation of FR & None & None \\
\hline \multirow[t]{5}{*}{ Patient group } & Platinum-resistant, ${ }^{a}$ relapse or refractory & Platinum-sensitive, ${ }^{b}$ first relapse \\
\hline & Age: $>18$ years & Age: $>18$ years \\
\hline & Pretreated with debulking surgery and at least one line & Pretreated with debulking surgery and first-line \\
\hline & platinum-based chemotherapy & platinum- and taxane-based chemotherapy \\
\hline & Measurable disease or elevated CAI 25 ( $2 \times$ ULN) & Measurable disease \\
\hline Enrollment & 412 & 1,100 \\
\hline \multirow[t]{3}{*}{ Interventions } & Arm I: $2.5 \mathrm{mg} / \mathrm{kg}$ farletuzumab plus PTX & Arm I: $1.25 \mathrm{mg} / \mathrm{kg}$ farletuzumab plus taxane $/$ CBDCA \\
\hline & Arm 2: Placebo plus PTX & Arm 2: $2.5 \mathrm{mg} / \mathrm{kg}$ farletuzumab plus taxane/CBDCA \\
\hline & & Arm 3: Placebo plus taxane/CBDCA \\
\hline Primary end point & PFS, OS & PFS \\
\hline Results summary & $\begin{array}{l}\text { This study was terminated due to the study not } \\
\text { meeting the prespecified criteria }\end{array}$ & No statistical difference \\
\hline
\end{tabular}

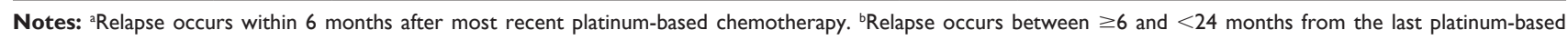
chemotherapy.

Abbreviations: FR, folate receptor; CA, cancer antigen; ULN, upper limit of normal; PTX, paclitaxel; CBDCA, carboplatin; PFS, progression-free survival; OS, overall survival. 
plus combination therapy, or placebo plus combination therapy. The primary end point was PFS. Secondary end points included OS, GCIG PFS, length of first vs second remission, tumor response, serologic response (CA125), quality of life, resource utilization, and pharmacokinetically assessed drug-drug interactions. The median PFS durations were $9.7,9.5$, and 9.0 months for $2.5 \mathrm{mg} / \mathrm{kg}$ farletuzumab, $1.25 \mathrm{mg} / \mathrm{kg}$ farletuzumab, and placebo, respectively (hazard ratio, 0.86 ; $95 \%$ confidence interval, $0.70-1.06$ for $2.5 \mathrm{mg} / \mathrm{kg}$ vs placebo). No significant differences in PFS among the treatment arms were observed. The primary end point of PFS was not met in this study. However, post hoc exploratory analysis revealed a trend toward improved PFS in some patient subsets. ${ }^{13,28}$

\section{Clinical data on lung cancer}

Lung cancer is a leading cause of cancer-related death worldwide. ${ }^{29,30}$ NSCLC constitutes $\sim 85 \%$ of lung cancers, and the median OS of patients with untreated advanced NSCLC is $<6$ months. Furthermore, the 1 -year OS rate is $10 \%$ at best. ${ }^{31}$ Thus, effective treatment for these patients is urgently needed.

A meta-analysis to verify the effectiveness of cytotoxic chemotherapy containing cisplatin for advanced NSCLC showed that platinum-based chemotherapy reduced the risk of mortality in these patients and improved symptom control and quality of life. ${ }^{32}$ However, the effect of chemotherapy remains insufficient. In recent years, targeted therapies using epidermal growth factor receptor (EGFR) tyrosine kinase inhibitors and anaplastic lymphoma kinase (ALK) inhibitors have continued to attract attention. For example, the EGFR tyrosine kinase inhibitor gefitinib prolonged PFS in patients with NSCLC having EGFR mutations as compared with paclitaxel-carboplatin combination therapy. ${ }^{33}$ However, EFGR mutations and translocations involving ALK only occur in $13 \%$ and $5 \%$ of patients with NSCLC, respectively. ${ }^{34}$ Thus, an alternative therapeutic target is essential for improving the prognosis of patients with advanced NSCLC.

Similar to ovarian cancer, $\mathrm{FR} \alpha$ expression is relatively higher in NSCLC tissues than in normal lung tissue. In addition, expression of FR $\alpha$ in lung adenocarcinoma is higher than that in squamous cell carcinoma..$^{5,35,36}$ Furthermore, some studies have revealed that FOLR 1 expression is also relatively higher in lung adenocarcinoma. ${ }^{37-39}$ These characteristics have become the rationale for developing a targeted therapy that is efficacious against NSCLC with mild AEs. Therefore, farletuzumab is expected to be a new treatment option against NSCLC.
Based on the aforementioned preclinical data and safety profile of farletuzumab in combination with carboplatintaxane doublet against EOC, a Phase II study involving patients with metastatic adenocarcinoma of the lung with FR $\alpha$-expressing tumors was conducted.

\section{NCT0I2I85I6}

This Phase II, double-blind, placebo-controlled study evaluated the efficacy of farletuzumab in patients with FR $\alpha$-positive metastatic adenocarcinoma of the lung. Importantly, in all patients, FR $\alpha$ expression of resected tumors was confirmed by immunohistochemistry using an antihuman FR monoclonal antibody. The primary end point was PFS, and the secondary end point was OS. Farletuzumab at a dose of $7.5 \mathrm{mg} / \mathrm{kg}$ was combined with a platinumcontaining doublet in chemonaïve patients. The following platinum-based regimens were allowed: carboplatin (AUC of 6) and paclitaxel $\left(200 \mathrm{mg} / \mathrm{m}^{2}\right)$, carboplatin (AUC of 5) and pemetrexed $\left(500 \mathrm{mg} / \mathrm{m}^{2}\right)$, and cisplatin $\left(75 \mathrm{mg} / \mathrm{m}^{2}\right)$ and pemetrexed $\left(500 \mathrm{mg} / \mathrm{m}^{2}\right)$. Four to six cycles of combination chemotherapy were administered on a triweekly schedule. Patients who achieve objective tumor shrinkage after combination therapy will receive maintenance therapy with a placebo or $7.5 \mathrm{mg} / \mathrm{kg}$ of farletuzumab every 3 weeks until documented disease progression. The target enrollment of a total of 130 patients has already been reached. However, the results of this study were not available at the time that this manuscript was submitted for publication. Therefore, at present, the clinical evidence is insufficient to establish the efficacy of farletuzumab for the treatment of NSCLC.

\section{Discussion}

Past clinical trials revealed that farletuzumab exhibited certain antitumor effects with slight side effects, as described earlier. However, the effectiveness of farletuzumab alone for cancer treatment remains insufficient. To realize the actual potential of farletuzumab, appropriate patient selection based on appropriate biomarkers and combination therapy with other agents is important (Figure 2).

Selecting appropriate patients through biomarker screening will facilitate the improvement of patient outcomes and decrease the degree of toxicity. ${ }^{40}$ We already confirmed FR $\alpha$ expression of malignant tumors in the clinical setting. ${ }^{41,42}$ However, the significance of FR $\alpha$ as a predictive/prognostic biomarker remains unclear, ${ }^{2}$ and the primary mechanism of action of farletuzumab has not yet been identified. The mechanisms of antitumor effects of monoclonal antibody therapy are believed to involve direct tumor targeting and indirect 


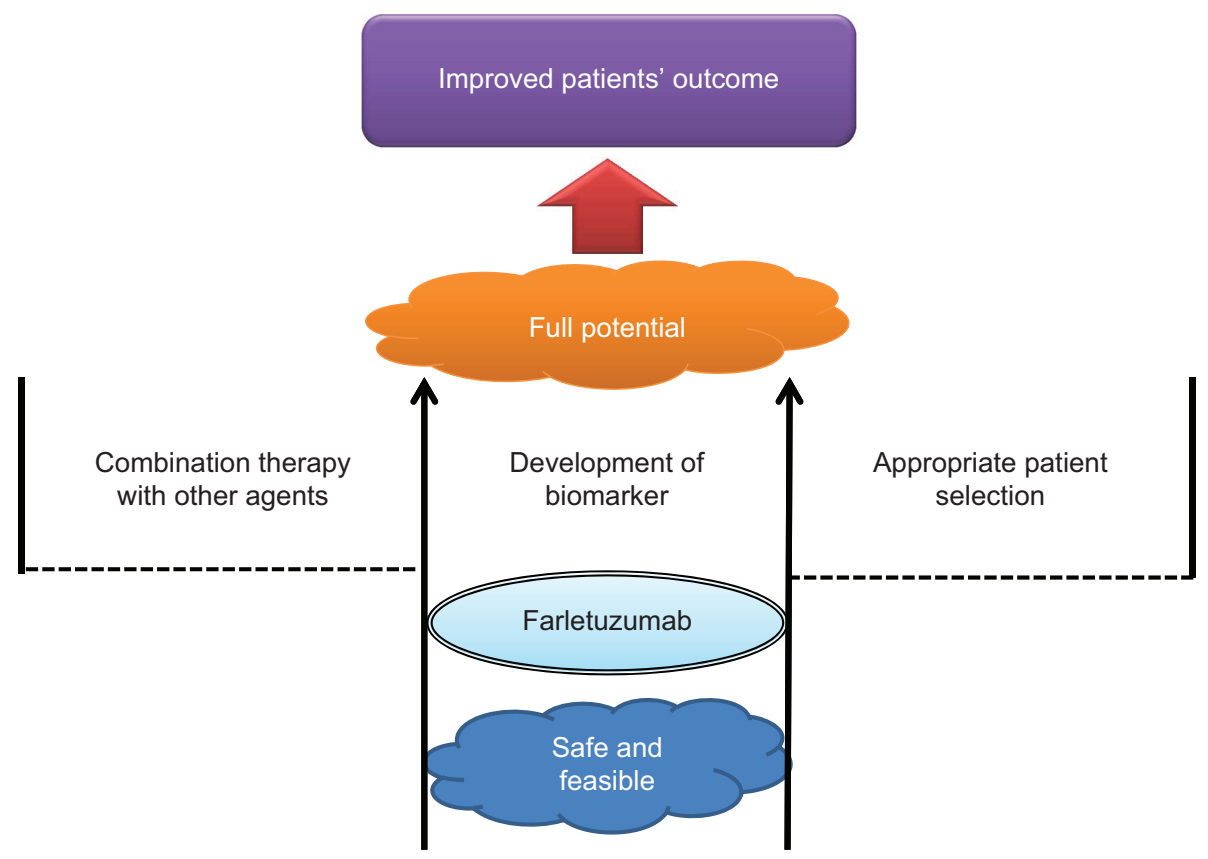

Figure 2 Overview of the future direction to maximize the potential of farletuzumab.

Notes: Farletuzumab is safe and feasible for use against solid tumors. To realize the actual potential of farletuzumab, appropriate patient selection based on appropriate biomarkers and combination therapy with other agents is important. Demonstration of the full potential of farletuzumab through future research is expected to result in an improvement in the prognosis of patients with solid tumors.

effects by enhancing immune responses. ${ }^{23}$ Farletuzumab exhibits tumor cytotoxicity mediated by antibody-dependent cellular cytotoxicity and CDC rather than blocking FR $\alpha$ mediated folate transport. ${ }^{8}$ A recent in vitro study showed that farletuzumab enhanced type 2 cell death of tumor cells due to late-stage autophagy. ${ }^{16}$ Hence, this mechanism may be considered the primary action of farletuzumab. ${ }^{16}$ However, the effectiveness of farletuzumab to increase autophagy of tumor cells is unpredictable. In other words, there is currently no biomarker to predict the effectiveness of treatment. Therefore, further studies are needed to identify the underlying mechanisms involved in the antitumor effects of farletuzumab.

Proliferation of cancer cells is not necessarily dependent on a single pathway. When cancer cells are exposed to an anticancer agent, they acquire resistance through a variety of bypass pathways. In lung cancer, interactions between $\mathrm{FR} \alpha$ expression and other molecular characteristics including EGFR mutation and ALK rearrangement, which are targets for treatment of lung cancer, are unclear. Hence, additional research to further elucidate the molecular biological mechanisms of the folate-related pathway is necessary. Bronte et $\mathrm{al}^{43}$ suggested that combination therapy, consisting of farletuzumab and pemetrexed, may have a synergic effect because both drugs target the folate pathway. However, worsening of AEs remains a concern. ${ }^{8}$ From the viewpoint of side effects, anticancer drugs, targeting molecules that are not associated with the folate pathway, for use in combination with farletuzumab are preferred. To this end, the combined effect of docetaxel and farletuzumab was confirmed in a recent in vitro study. ${ }^{16}$ Based on these outcomes, future clinical applications for treating EOC and NSCLC are expected.

\section{Conclusion}

Phase I/II clinical trials clearly demonstrated the feasibility and safety of farletuzumab as a treatment option against solid tumors. In contrast, a Phase III clinical trial that was conducted to verify the effect of paclitaxel-carboplatin therapy combined with farletuzumab for patients with recurrent EOC found that improvement in PFS was not statistically significant, which might be due to the fact that the eligibility criteria for this study did not include FR $\alpha$ expression. The significance of $\mathrm{FR} \alpha$ as a predictive/prognostic biomarker remains unclear. In addition, at present, there is no biomarker to predict the response and toxicities of patients treated with farletuzumab. Furthermore, the primary mechanism of action of farletuzumab has not yet been identified. Therefore, further research to discern the underlying mechanism of farletuzumab in tumor suppression is necessary to clarify the full potential of this chemotherapeutic agent.

\section{Disclosure}

The authors report no conflicts of interest and received no financial support associated with this article. 


\section{References}

1. Kelemen LE. The role of folate receptor alpha in cancer development, progression and treatment: cause, consequence or innocent bystander? Int J Cancer. 2006;119(2):243-250.

2. Ledermann JA, Canevari S, Thigpen T. Targeting the folate receptor: diagnostic and therapeutic approaches to personalize cancer treatments Ann Oncol. 2015;26(10):2034-2043.

3. Chen YL, Chang MC, Huang CY, et al. Serous ovarian carcinoma patients with high alpha-folate receptor had reducing survival and cytotoxic chemo-response. Mol Oncol. 2012;6(3):360-369.

4. Kalli KR, Oberg AL, Keeney GL, et al. Folate receptor alpha as a tumor target in epithelial ovarian cancer. Gynecol Oncol. 2008;108(3): 619-626.

5. Iwakiri S, Sonobe M, Nagai S, Hirata T, Wada H, Miyahara R. Expression status of folate receptor alpha is significantly correlated with prognosis in non-small-cell lung cancers. Ann Surg Oncol. 2008;15(3):889-899.

6. O'Shannessy DJ, Yu G, Smale R, et al. Folate receptor alpha expression in lung cancer: diagnostic and prognostic significance. Oncotarget. 2012; 3(4):414-425.

7. Marchetti C, Palaia I, Giorgini M, et al. Targeted drug delivery via folate receptors in recurrent ovarian cancer: a review. Onco Targets Ther. 2014;7 1223-1236.

8. Shi H, Guo J, Li C, Wang Z. A current review of folate receptor alpha as a potential tumor target in non-small-cell lung cancer. Drug Des Devel Ther. 2015;9:4989-4996.

9. Ebel W, Routhier EL, Foley B, et al. Preclinical evaluation of MORAb003, a humanized monoclonal antibody antagonizing folate receptoralpha. Cancer Immun. 2007; 7:6.

10. Thomas A, Maltzman J, Hassan R. Farletuzumab in lung cancer. Lung Cancer. 2013;80(1):15-18.

11. Lin J, Spidel JL, Maddage CJ, et al. The antitumor activity of the human FOLR1-specific monoclonal antibody, farletuzumab, in an ovarian cancer mouse model is mediated by antibody-dependent cellular cytotoxicity. Cancer Biol Ther. 2013;14(11):1032-1038.

12. Spannuth WA, Sood AK, Coleman RL. Farletuzumab in epithelial ovarian carcinoma. Expert Opin Biol Ther. 2010;10(3):431-437.

13. Vergote I, Armstrong D, Scambia G, et al. Phase III double-blind, placebo-controlled study of weekly farletuzumab with carboplatin/ taxane in subjects with platinum-sensitive ovarian cancer in first relapse. Int J Gynecol Cancer. 2013;23(8 Suppl 1):11.

14. Kamen BA, Smith AK. Farletuzumab, an anti-folate receptor alpha antibody, does not block binding of folate or anti-folates to receptor nor does it alter the potency of anti-folates in vitro. Cancer Chemother Pharmacol. 2012;70(1):113-120.

15. Miotti S, Bagnoli M, Tomassetti A, Colnaghi MI, Canevari S. Interaction of folate receptor with signaling molecules lyn and G(alpha)(i-3) in detergent-resistant complexes from the ovary carcinoma cell line IGROV1. J Cell Sci. 2000;113 Pt 2:349-357.

16. Wen Y, Graybill WS, Previs RA, et al. Immunotherapy targeting folate receptor induces cell death associated with autophagy in ovarian cancer. Clin Cancer Res. 2015;21(2):448-459.

17. Armstrong DK, Brady MF. Intraperitoneal therapy for ovarian cancer: a treatment ready for prime time. J Clin Oncol. 2006;24(28):4531-4533.

18. Sato S, Itamochi H. Ovarian cancer and drug resistance. Curr Obstet Gynecol Rep. 2015;4(1):18-25.

19. Sato S, Itamochi H. Neoadjuvant chemotherapy in advanced ovarian cancer: latest results and place in therapy. Ther Adv Med Oncol. 2014;6(6): 293-304

20. Cannistra SA. Cancer of the ovary. N Engl J Med. 2004;351(24):2519-2529.

21. Jelovac D, Armstrong DK. Role of farletuzumab in epithelial ovarian carcinoma. Curr Pharm Des. 2012;18(25):3812-3815.

22. Kudlowitz D, Teplinsky E, Muggia F. Integrating targeted drugs with taxanes and platinums: opportunities and challenges. Transl Cancer Res. 2015;4(1):127-136.

23. Konner JA, Bell-McGuinn KM, Sabbatini P, et al. Farletuzumab, a humanized monoclonal antibody against folate receptor alpha, in epithelial ovarian cancer: a phase I study. Clin Cancer Res. 2010;16(21): 5288-5295.
24. Farrell C, Schweizer C, Wustner J, et al. Population pharmacokinetics of farletuzumab, a humanized monoclonal antibody against folate receptor alpha, in epithelial ovarian cancer. Cancer Chemother Pharmacol. 2012;70(5):727-734.

25. Kim KH, Jelovac D, Armstrong DK, et al. Phase $1 \mathrm{~b}$ safety study of farletuzumab, carboplatin and pegylated liposomal doxorubicin in patients with platinum-sensitive epithelial ovarian cancer. Gynecol Oncol. 2016;140(2):210-214.

26. Sasaki Y, Miwa K, Yamashita K, et al. A phase I study of farletuzumab, a humanized anti-folate receptor alpha monoclonal antibody, in patients with solid tumors. Invest New Drugs. 2015;33(2):332-340.

27. Armstrong DK, White AJ, Weil SC, Phillips M, Coleman RL. Farletuzumab (a monoclonal antibody against folate receptor alpha) in relapsed platinum-sensitive ovarian cancer. Gynecol Oncol. 2013;129(3): $452-458$.

28. Walters CL, Arend RC, Armstrong DK, Naumann RW, Alvarez RD. Folate and folate receptor alpha antagonists mechanism of action in ovarian cancer. Gynecol Oncol. 2013;131(2):493-498.

29. Goldstraw P, Crowley J, Chansky K, et al. The IASLC Lung Cancer Staging Project: proposals for the revision of the TNM stage groupings in the forthcoming (seventh) edition of the TNM Classification of malignant tumours. $J$ Thorac Oncol. 2007;2(8):706-714.

30. Jemal A, Siegel R, Xu J, Ward E. Cancer statistics, 2010. CA Cancer J Clin. 2010;60(5):277-300.

31. Schiller JH, Harrington D, Belani CP, et al. Comparison of four chemotherapy regimens for advanced non-small-cell lung cancer. $N$ Engl J Med. 2002;346(2):92-98.

32. Non-small Cell Lung Cancer Collaborative Group. Chemotherapy in non-small cell lung cancer: a meta-analysis using updated data on individual patients from 52 randomised clinical trials. BMJ. 1995;311(7010): 899-909.

33. Mok TS, Wu YL, Thongprasert S, et al. Gefitinib or carboplatinpaclitaxel in pulmonary adenocarcinoma. NEngl J Med. 2009;361(10): 947-957.

34. Sequist LV, Heist RS, Shaw AT, et al. Implementing multiplexed genotyping of non-small-cell lung cancers into routine clinical practice. Ann Oncol. 2011;22(12):2616-2624.

35. Franklin WA, Waintrub M, Edwards D, et al. New anti-lung-cancer antibody cluster 12 reacts with human folate receptors present on adenocarcinoma. Int J Cancer Suppl. 1994;8:89-95.

36. Nunez MI, Behrens C, Woods DM, et al. High expression of folate receptor alpha in lung cancer correlates with adenocarcinoma histology and EGFR [corrected] mutation. J Thorac Oncol. 2012;7(5):833-840.

37. Kikuchi T, Daigo Y, Katagiri T, et al. Expression profiles of non-small cell lung cancers on cDNA microarrays: identification of genes for prediction of lymph-node metastasis and sensitivity to anti-cancer drugs. Oncogene. 2003;22(14):2192-2205.

38. Garber ME, Troyanskaya OG, Schluens K, et al. Diversity of gene expression in adenocarcinoma of the lung. Proc Natl Acad Sci US A. 2001;98(24):13784-13789.

39. Bhattacharjee A, Richards WG, Staunton J, et al. Classification of human lung carcinomas by mRNA expression profiling reveals distinct adenocarcinoma subclasses. Proc Natl Acad Sci U S A. 2001;98(24): 13790-13795.

40. Leamon CP, Lovejoy CD, Nguyen B. Patient selection and targeted treatment in the management of platinum-resistant ovarian cancer. Pharmgenomics Pers Med. 2013;6:113-125.

41. Maurer AH, Elsinga P, Fanti S, Nguyen B, Oyen WJ, Weber WA. Imaging the folate receptor on cancer cells with $99 \mathrm{mTc}$-etarfolatide: properties, clinical use, and future potential of folate receptor imaging. J Nucl Med. 2014;55(5):701-704.

42. Kim MH, Kim WH, Kim CG, Kim DW. Synthesis and evaluation of $(99 \mathrm{~m}) \mathrm{Tc}$-labeled folate-tripeptide conjugate as a folate receptor-targeted imaging agent in a tumor-bearing mouse model. Nucl Med Mol Imaging. 2015;49(3):200-207.

43. Bronte G, Lo Vullo F, Pernice G, et al. Farletuzumab for NSCLC: exploiting a well-known metabolic pathway for a new therapeutic strategy. Expert Opin Investig Drugs. 2015;24(1):125-132. 


\section{Publish your work in this journal}

OncoTargets and Therapy is an international, peer-reviewed, open access journal focusing on the pathological basis of all cancers, potential targets for therapy and treatment protocols employed to improve the management of cancer patients. The journal also focuses on the impact of management programs and new therapeutic agents and protocols on

patient perspectives such as quality of life, adherence and satisfaction. The manuscript management system is completely online and includes a very quick and fair peer-review system, which is all easy to use. Visit http://www.dovepress.com/testimonials.php to read real quotes from published authors.

Submit your manuscript here: http://www.dovepress.com/oncotargets-and-therapy-journal 